\title{
Role of Diet in the Determination of Jejunal Sucrase Activity in the Weanling Rat
}

\author{
SUSAN J. HENNING ${ }^{(38)}$ AND DOLORES M. GUERIN \\ Department of Biology, University of Houston, Houston, Texas, USA
}

\begin{abstract}
Summary
This study was designed to determine the critical difference between rat milk and rat chow with respect to their effects on jejunal sucrase activity during the fourth postnatal wk. Rats were weaned onto special diets on postnatal day 17 , and jejunal sucrase was assayed on day 28 . A pelleted diet containing lactose as sole carbohydrate did not cause depression of sucrase activity. Sucrase values $(\mu \mathrm{moles} / \mathrm{hr} / \mathrm{mg}$ protein) were $10.49 \pm 0.81(n=15)$ for the lactose chow and $6.65 \pm 0.29(n=16)$ for the sucrose chow. This indicates that the nature of the dietary carbohydrate does not account for the sucrase differences of weaned and nonweaned animals. Likewise, the physical consistency of the diet is unimportant because sucrase values were just as high on a liquid diet $(10.91 \pm 0.77 \mu$ moles $/ \mathrm{hr} / \mathrm{mg}$ protein; $\boldsymbol{n}=8)$ as on the solid diets. However, when the relative proportions of carbohydrate and fat in the diet were varied, there were significant effects on sucrase activity; values on a low carbohydrate diet $(4.30 \pm 0.33 \mu$ moles/ $\mathrm{hr} / \mathrm{mg}$ protein; $n=8$ ) being less than one-half those on a high carbohydrate diet $(10.91 \pm 0.77 \mu$ moles $/ \mathrm{hr} / \mathrm{mg}$ protein; $n=8)$.
\end{abstract}

\section{Speculation}

The terminal maturation of jejunal sucrase is dependent on the normal process of weaning. The critical feature of the weanling diet is that it is a high-carbohydrate, low-fat diet. In the absence of this dietary transition, intestinal development remains incomplete.

The postnatal development of the rat small intestine is characterized by an array of enzymic changes during the third wk of life. Some enzymes (such as lactase and the lysosomal hydrolases) which have high activities at birth, decline at this time; others (such as maltase and sucrase) show dramatic increases in their activities. The details of these enzymic changes and their importance in the dietary transition from milk to solid food have been frequently reviewed $(6,15,16,19,27)$. There is good evidence to indicate that the enzymic changes are cued by the glucocorticoid $(4,8,14,15,16,18,22)$ and the thyroid $(13,20,21,34)$ hormones. Although there is a temporal correlation between the maturation of the intestinal mucosa and the spontaneous process of weaning, the possibility that the ontogenic changes in the intestine are diet initiated has generally been discredited $(4,10,17,23)$. For instance, rat pups which are prevented from weaning show an initial rise of jejunal sucrase at 17 days of age, just as in control pups (17). However, the same study showed that by the fourth postnatal wk, diet is an important determinant of sucrase activity. In control (weaned) pups, sucrase activity had plateaued at adult levels by day 27 , whereas nonweaned pups had enzyme activities less than one-half those of controls and equivalent to activities usually seen on approximately day 20 (17). Thus, it seems that the normal process of weaning is necessary for the terminal maturation of jejunal sucrase activity. The aim of the current study was to determine the critical feature of the dietary change from milk to chow which accounts for this role of weaning in intestinal development. Three aspects of the dietary change have been examined:
(1) the nature of the carbohydrate; (2) the physical consistency; and (3) the proportion of carbohydrate relative to fat.

\section{MATERIALS AND METHODS}

\section{CHEMICALS}

Sucrose used for assay of sucrase was ultra pure grade (Schwarz/ Mann, Orangeburg, NY). Glucose was measured using Statzyme Glucose $(500 \mathrm{~nm})$ from Worthington Biochemical Corp. (Freehold, NJ). It was necessary to dissolve this reagent in $100 \mathrm{mM}$ Tris ( $\mathrm{pH} 7.4$ ) instead of water, to inhibit residual sucrase activity. Bovine serum albumin (Sigma Chemical Co., St. Louis, MO) was used as the protein standard. All other chemicals were reagent grade.

\section{ANIMALS}

Pregnant rats of the Sprague-Dawley strain (Charles River CD) were received from Charles River Breeding Laboratories (Wilmington, MA) on the 15th day of gestation. They were housed in air-conditioned quarters $\left(21 \pm 1^{\circ} \mathrm{C}\right)$ with lights on between 0500 and $1700 \mathrm{hr}$. On the due date, cages were checked every $2 \mathrm{hr}$ for the presence of pups. The birthdate was regarded as day 0 . Approximately $24 \mathrm{hr}$ postpartum, all litters were reduced to nine pups. Each litter was housed with its mother with food (Purina Lab Chow) and water available ad libitum until day 17 when experiments were begun by removal of mothers and institution of special diets.

\section{DIETS AND PROCEDURES}

Experiment 1. Solid Diets. Two litters were weaned onto each of three solid diets on day 17 and were allowed to feed ad libitum until day 28 when all pups were sacrificed for assay of jejunal sucrase. The three diets were: standard chow, lactose chow, and sucrose chow. Standard chow was Purina Lab Chow (Ralston Purina Co., St. Louis, MO). Lactose and sucrose chows were prepared by U.S. Biochemical Corp. (Cleveland, $\mathrm{OH}$ ) in pelleted form using Normal Protein Test Diet with starch (i.e., $100 \%$ of the carbohydrate) replaced by lactose and sucrose, respectively. The composition of the diets is given in Table 1.

Experiment 2. Liquid Diets. At day 17, eight pups were weaned onto a high fat liquid diet, and eight pups were weaned onto a high carbohydrate liquid diet. The pups were housed in groups of four, and diets were administered in calibrated bottles with sipper tubes. Preliminary experiments showed that the diets coagulated in the feeding tube if left overnight at room temperature. To avoid this problem, each feeding bottle was provided with an ice jacket consisting of a larger plastic bottle filled with ice and water. Fresh diet was provided twice daily (at approximately 0900 and 1700 $\mathrm{hr}$ ), and the volume consumed was noted. All pups were sacrificed on day 28 for assay of jejunal sucrase activity.

High-fat liquid diet consisted of whole cow's milk and heavy cream in a ratio of $40 \mathrm{~g}$ fat: $100 \mathrm{~g}$ solute. Because cow's milk contains $0.114 \mathrm{~g}$ solute per $\mathrm{ml}$ and heavy cream contains $50 \%$ by volume of fat, this ratio was achieved by mixing $6.9 \mathrm{ml}$ cream 
Table 1. Composition of Diets

\begin{tabular}{|c|c|c|c|c|c|c|}
\hline & \multicolumn{3}{|c|}{$\begin{array}{l}\text { Composition } \\
\text { (g/100 g solids) }\end{array}$} & \multicolumn{2}{|c|}{ Caloric density } & \multirow{2}{*}{$\begin{array}{c}\text { Nature of } \\
\text { carbohydrate }\end{array}$} \\
\hline 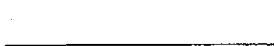 & Carbohydrate & Fat & Protein & $\mathrm{kcal} / 100 \mathrm{~g}$ solids & $\mathrm{kcal} / 100 \mathrm{ml}$ & \\
\hline \multicolumn{7}{|l|}{ Solid diets } \\
\hline Standard chow & 61 & 5 & 26 & 393 & & Mixed \\
\hline Lactose chow & 59 & 10 & 27 & 434 & & $100 \%$ lactose \\
\hline Sucrose chow & 59 & 10 & 27 & 434 & & $100 \%$ sucrose \\
\hline \multicolumn{7}{|l|}{ Liquid diets } \\
\hline Rat milk & 12 & 47 & 35 & 611 & 159.0 & $100 \%$ lactose \\
\hline Low carbohydrate & 29 & 50 & 21 & 650 & 96.2 & $100 \%$ lactose \\
\hline High carbohydrate & 59 & 21 & 21 & 509 & 83.2 & $100 \%$ lactose \\
\hline
\end{tabular}

${ }^{1}$ From Ref. 9.

with $87.7 \mathrm{ml}$ whole milk. High-carbohydrate liquid diet consisted of whole cow's milk with solid lactose (Sigma Chemical Co.) added in a ratio of $44.0 \mathrm{~g}$ lactose: $100 \mathrm{~g}$ milk solids (i.e., $4.4 \mathrm{~g}$ lactose: $87.7 \mathrm{ml}$ milk). To dissolve the lactose the mixture was heated almost to boiling while stirring. The composition of both liquid diets is shown in Table 1. The composition of rat milk (9) is included for comparison.

\section{ASSAY OF JEJUNAL SUCRASE}

At 28 days of age animals were killed by decapitation. The small intestine from the ligament of Treitz to the ileocecal junction was removed. The distal half was discarded, and the proximal half (defined as the jejunum) was flushed thoroughly with ice-cold $\mathrm{NaCl}$ solution $(0.9 \%)$. Sucrase was assayed in the mid-jejunum where it has maximal activity (10). For this purpose, the middle $10 \mathrm{~cm}$ of the jejunum was slit lengthwise and scraped with a steel spatula to remove mucosa. Homogenates of mucosa were prepared in 9 volumes $0.154 \mathrm{M} \mathrm{KCl}$ by nine stròkes (approximately $45 \mathrm{sec}$ ) of a Potter Elvehjem Teflon/glass homogenizer. Enzymic activity in $0.1 \mathrm{ml}$ homogenate was measured by incubating at $37^{\circ} \mathrm{C}$ with $0.4 \mathrm{ml} 62.5 \mathrm{mM}$ sodium maleate buffer ( $\mathrm{pH} 6.0$ ) containing $0.3 \mathrm{M}$ sucrose. The reaction was stopped by precipitation of protein with $0.2 \mathrm{ml} 1.8 \% \mathrm{Ba}(\mathrm{OH})_{2} \cdot 8 \mathrm{H}_{2} \mathrm{O}$, and the mixture was then neutralized with $0.2 \mathrm{ml} 2 \% \mathrm{ZnSO}_{4} \cdot 7 \mathrm{H}_{2} \mathrm{O}$. Glucose produced from sucrose was measured with glucose oxidase reagent. Corrections were made for endogenous glucose in the tissue and in the substrate. This method for assay of sucrase activity is essentially the same as that originally described by Doell and Kretchmer (8). Protein was determined in duplicate by the method of Lowry et al. (26). Sucrase activities were expressed as $\mu$ moles of glucose produced/ $\mathrm{hr} / \mathrm{mg}$ mucosal protein.

\section{STATISTICS}

All results are reported as mean \pm S.E. Differences between means were evaluated by Student's $t$ test for unpaired values.

\section{RESULTS}

To determine whether the low sucrase activities of nonweaned pups is due to the fact that lactose is essentially the sole carbohydrate in milk, pups were weaned onto pelleted diets containing either sucrose or lactose as sole carbohydrate. The results are shown in Figure 1 and are compared with those of pups weaned onto standard chow. It can be seen that there was certainly no depression of jejunal sucrase activity by the lactose diet. In fact, the pups on this diet had sucrase activities that were significantly higher than those of pups on both standard chow and sucrose chow.

To check for the possibility that changes in total mucosal protein may have influenced the sucrase specific activity values in Figure 3, total sucrase activity was calculated. The values were $29.88 \pm 2.77,50.14 \pm 6.24$, and $32.95 \pm 1.75 \mu \mathrm{moles} / \mathrm{hr} / \mathrm{mid} 10$ $\mathrm{cm}$ jejunum for standard, lactose and sucrose chows, respectively.

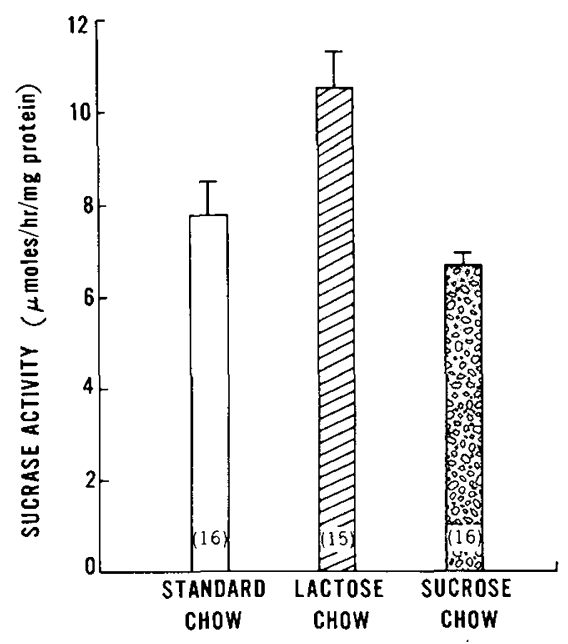

Fig. 1. Jejunal sucrase activities of pups on solid diets varying in the nature of the carbohydrate. Six litters were used for this experiment. Mothers were removed on day 17 and from then on two litters were fed standard chow $(\square)$, two litters were fed lactose chow (囚), and two litters were fed sucrose chow (团). All pups were sacrificed on day 28. Jejunal sucrase activities are given as mean \pm S.E. The number of animals in each dietary group is indicated at the base of the column. For standard chow versus lactose chow and for lactose chow versus sucrose chow, the activity differences are significant $(P<0.02$ and $P<0.001$, respectively). For standard chow versus sucrose chow, the difference is NS $(P>0.1)$.

These values lead to the same conclusions as do the specific activities of Figure 3, i.e., that the feeding of a solid diet containing lactose as sole carbohydrate from days 17 to 28 does not result in reduction of sucrase activity.

The growth of pups on the three solid diets is shown in Figure 2. As previously noted (24), premature weaning (day 17) onto standard chow results in an arrest of growth for approximately 3 days. This problem was not so severe with the lactose chow and was nonexistent with the sucrose chow.

To determine whether jejunal sucrase activities are affected by the physical consistency of the diet, we prepared a liquid diet which had the same percentage carbohydrate as the lactose chow used in Figure 1. When eight pups were weaned onto this diet at day 17 , their jejunal sucrase activities on day 28 (10.91 \pm 0.77 $\mu$ moles $/ \mathrm{hr} / \mathrm{mg}$ protein) were not significantly different from those of pups on lactose chow (Fig. 1). This demonstration that sucrase activity is unaffected by the physical consistency of the diet allowed the use of liquid diets in the investigation of the role of the relative proportions of carbohydrate and fat.

Rat milk is low in carbohydrate and high in fat (Table 1), and the converse is true of the normal weanling diet (chow). To investigate whether this difference in relative proportion accounts for the depressed sucrase values in nonweaned rats (17), pups were weaned onto either a liquid diet that mimicked rat milk in 
composition (low carbohydrate) or a liquid diet that mimicked chow (high carbohydrate). Figure 3 shows that by day 28 there was a striking difference in the jejunal sucrase activities of the two groups. Pups on the low carbohydrate diet had sucrase specific activity values only $39 \%$ those on the high carbohydrate diet (Fig. 3 ). When calculated as total sucrase activity in the mucosa, the low carbohydrate group showed values $46 \%$ those of the high carbohydrate group $(P<0.001)$. This difference is virtually identical to that previously reported (17) for nonweaned as compared with normally weaned pups.

As undernutrition has been shown to depress various disaccharidase activites in the jejunal mucosa (12), it is necessary to consider whether the low sucrase values for pups on the low carbohydrate diet (Fig. 3) could be the result of undernutrition

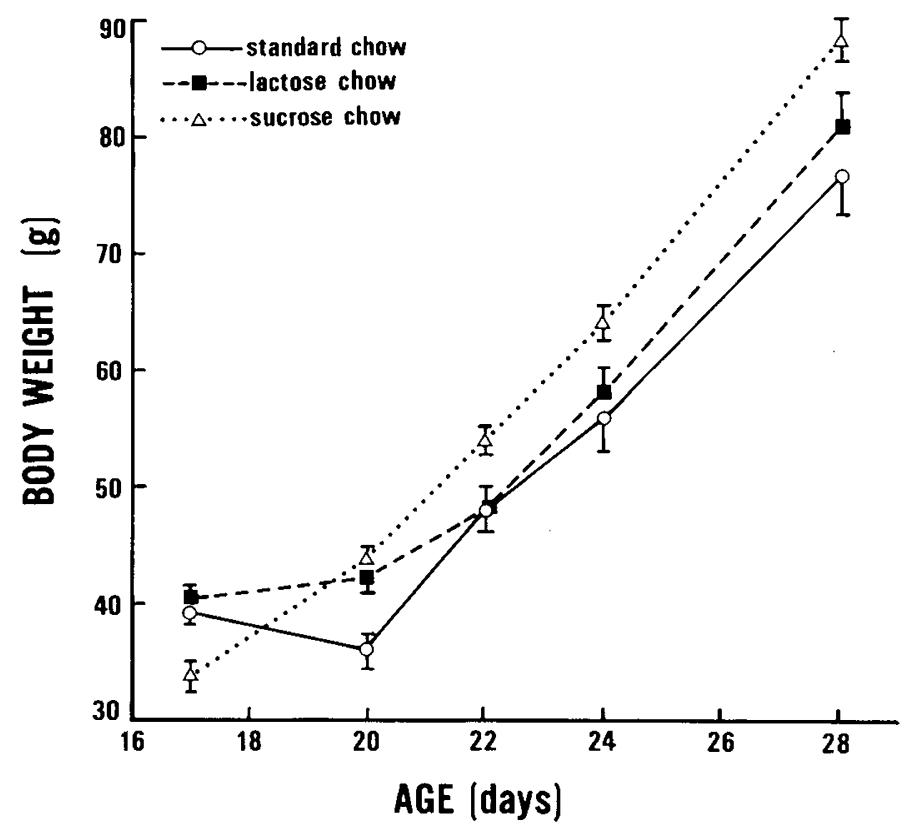

Fig. 2. Growth of the three groups of pups from Figure 1. Values for body weight are given as mean \pm S.E.

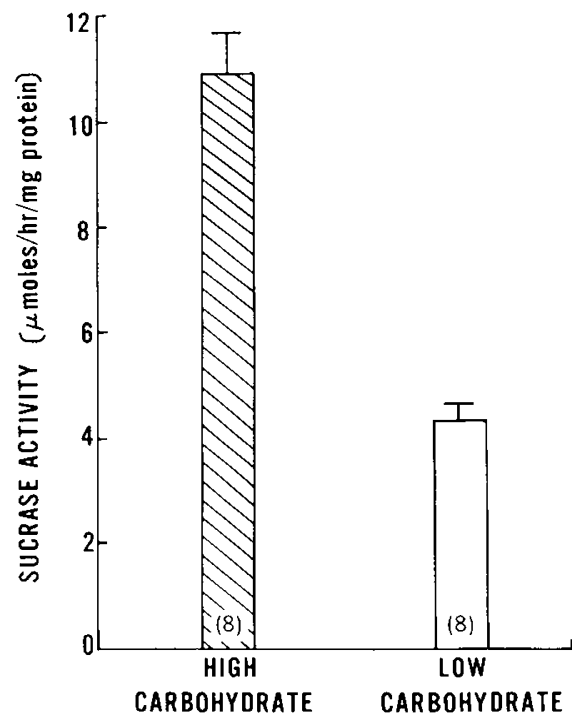

Fig. 3. Jejunal sucrase activities of pups on liquid diets varying in the relative proportion of carbohydrate and fat. Sixteen pups were used for this experiment. Mothers were removed on day 17 and from then on eight pups were fed high carbohydrate liquid diet $(\mathbb{Q})$ and the other eight pups were fed low carbohydrate liquid diet $(\square)$. All pups were sacrificed on day 28. Jejunal sucrase activities are given as mean \pm S.E. The difference between the two diets is highly significant $(P<0.001)$. rather than dietary composition. The results in Figure 4 show that pups actually grew just as well on the low carbohydrate diet as on the high carbohydrate diet. Thus, the differences in their sucrase activities (Fig. 3) must be due to the dietary composition rather than to difference in nourishment. This is further attested to by comparing the growth of pups on solid (Fig. 2) and liquid diets (Fig. 4). By day 28 , both liquid diets resulted in significantly lower body weights than those seen for any of the solid diets. Despite this, the pups on the high carbohydrate liquid diet had sucrase activities as high as the highest seen on the solid diets.

With respect to the results in Figure 3, another possible complication was that the sucrase differences might be due to a different pattern of feeding on the two diets. In adult rats, there is a circadian fluctuation of sucrase activities with peak values while feeding (normally at night) and minimal values while resting (32). During development, the sucrase rhythm normally appears by day 22 (1). If pups on the high and low carbohydrate liquid diets (Fig. 3) fed predominantly in the day and night, respectively, the sucrase differences shown in Figure 3 could have been independent of the dietary composition. To assess this potential artifact, we have plotted the daily consumption of diet during the last 7 days of the experiment (Fig. 5). It can be seen that on both diets the pattern

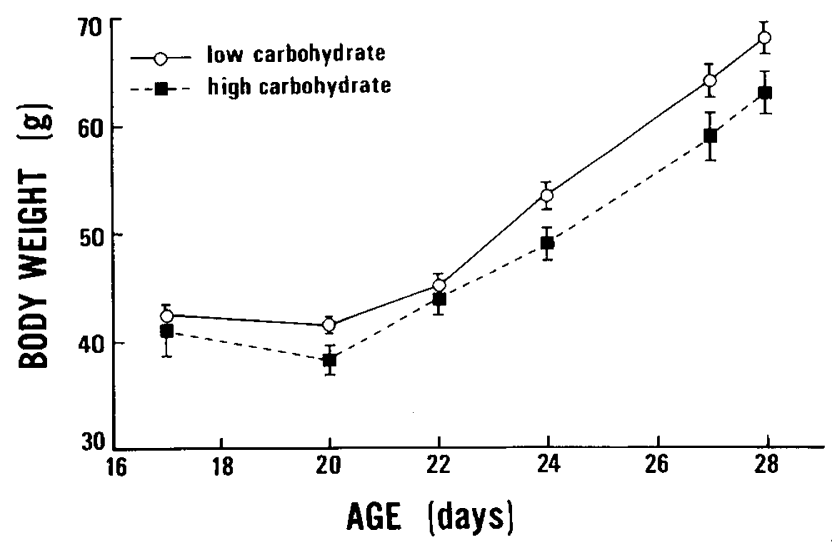

Fig. 4. Growth of the two groups of pups from Figure 3. Values for body weight are given as mean \pm S.E. Differences between the two groups reach statistical significance only on day $24(P<0.05)$.

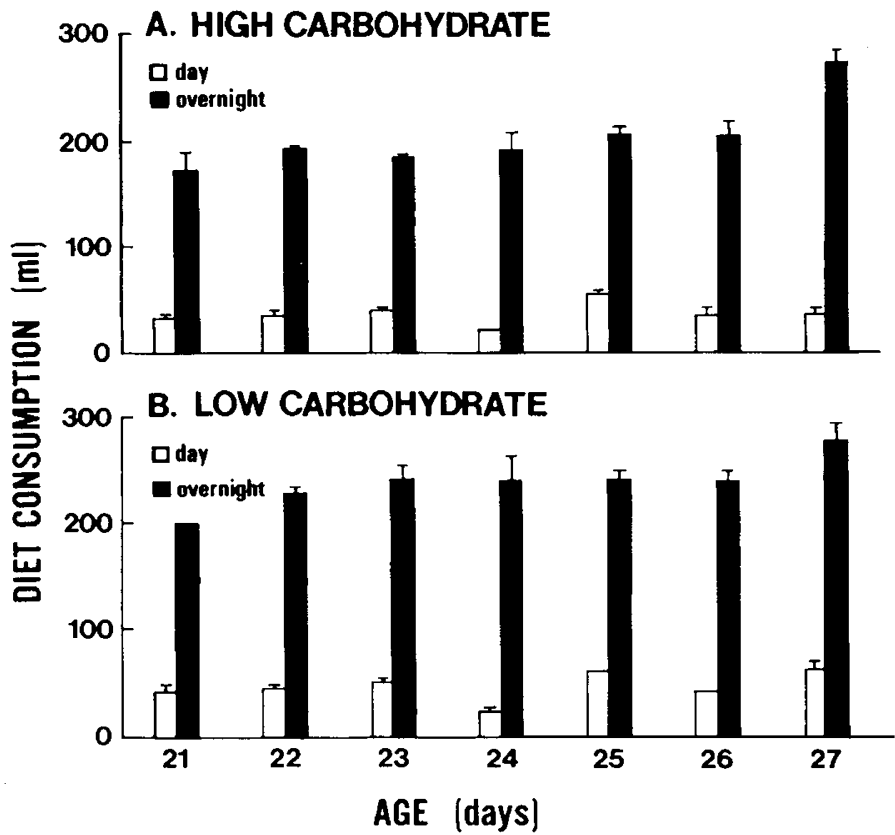

Fig. 5. Daily pattern of dietary consumption by the two groups of pups from Figure 3 and 4 . Values are given as mean volume consumed per cage (four pups) during the day ( $\square$ ) and overnight ( $\square$ ). Error bars show the range for the two cages of pups receiving each diet. Lack of error bars indicates that the difference was less than $1 \mathrm{ml}$. 
of feeding was predominantly nocturnal as is normal for pups of these ages (1). Thus, the results in Figure 3 are not complicated by differences in feeding patterns and can firmly be ascribed to differences in dietary composition.

Considering the caloric information in Table 1 together with the consumption values in Figure 5, it is apparent that the caloric intake was greater on the low carbohydrate diet than on the high carbohydrate diet. For instance, the mean intake $( \pm$ S.E. $)$ for days 22 to 26 was $138.1 \pm 3.1$ and $98.2 \pm 3.8 \mathrm{kcal} /$ day for the low and high carbohydrate diets, respectively $(n=5 ; P<0.001)$. This further affirms the point made earlier that the low sucrase activities of animals on the low carbohydrate diet (Fig. 3) cannot be due to undernutrition.

\section{DISCUSSION}

The aim of this study was to determine the feature of the weanling diet which accounts for the final rise of jejunal sucrase during development. We have examined the key differences between rat milk and rat chow in relation to their abilities to account for the fact that in the fourth postnatal wk nonweaned pups have sucrase activities approximately $45 \%$ those of weaned pups (17). The results indicate that the terminal maturation of the enzyme is independent of both the nature of the carbohydrate in the diet (lactose versus sucrose versus mixed carbohydrate) and the physical consistency of the diet (liquid versus solid). Instead, the effect of diet is due to the relative proportion of carbohydrate and fat. The critical feature of the normal weanling diet is that it is a high carbohydrate, low fat diet. The possibility that this aspect of the dietary change of weaning is also essential for the terminal maturation of other intestinal enzymes is currently under investigation.

For the adult rat, there are conflicting reports as to the effect of dietary carbohydrate on jejunal sucrase activities. Blair et al. (2) found that the nature of the carbohydrate was important, as animals on sucrose diets had sucrase activities almost double those of animals on lactose, glucose, or carbohydrate-free diets. In contrast, Deren et al. (7) found no difference in the ability of sucrose and glucose to elevate sucrase values over those seen on a carbohydrate-free diet. In view of the results of the present study, a likely explanation of the differences between these two adult studies lies in the fact that the rats used by Deren et al. were considerably younger than those used by Blair et al. (150 and 250 $\mathrm{g}$, respectively). It seems reasonable to suppose that in weanlings and young adults, the enzyme responds predominantly to the proportion of carbohydrate in the diet, whereas in older animals the nature of the carbohydrate becomes the critical factor.

In adult humans, jejunal sucrase activity is higher on diets containing glucose than on carbohydrate-free diets (11), but also is higher on sucrose diets than on glucose diets (30). Thus, in adult humans, the enzyme is responsive to both the amount of carbohydrate in the diet and the nature of the carbohydrate. Considering the results of the present study, it is possible that in the human infant jejunal sucrase responds only to the proportion of carbohydrate in the diet and not to the nature of the carbohydrate.

In relation to the investigation reported here, it should be noted that as both carbohydrate and fat were varied, the critical feature of the weanling diet may be either its high proportion of carbohydrate or its low proportion of fat. Experiments to differentiate between the two are currently in progress.

Also remaining to be established is whether the effect observed in Figure 3 represents a direct action of dietary components on the intestinal epithelium or is under hormonal mediation. In the adult rat, it has been shown that the elevation of sucrase activity on a high sucrose diet is due to an effect on the proliferating cells of the intestinal crypts rather than on the differentiated cells of the villus $(29,33)$. Although this portends hormonal mediation, at present there is no confirming evidence. Furthermore, there is no hormone that is an obvious candidate for the role. Insulin concentrations would be elevated on a high carbohydrate diet, but it is unlikely that this would stimulate sucrase activity because increased disaccharidase activities are characteristic of diabetes (28,
35 ) and intravenous administration of carbohydrate does not elevate sucrase (5). Glucocorticoids are known to elicit increased sucrase activity in neonatal rats, but the enzyme loses responsiveness to these hormones towards the end of the third postnatal wk (17).

One of the unexpected results of this study was that sucrase activity was higher on lactose chow than on sucrose chow or standard chow (Fig. 1). In view of the fact that these animals showed signs of diarrhea and yet grew as well as controls, it is possible that the elevation of sucrase on this diet was secondary to increased food intake. This in turn would lead to increased production of the hormone gastrin which is known to have a powerful trophic effect on intestinal mucosa, including increased disaccharidase activity (25).

Our observations regarding the growth of prematurely weaned animals may be of value to other investigators. Both the sucrose and lactose chows gave significantly better growth rates on days 17 to 20 than did standard chow. There are three differences that could account for this-the sucrose and lactose chows were: (1) softer; (2) of higher fat content; and (3) sweeter, than the standard chow. It is tempting to conclude that the last is the most important factor because this would also account for the fact that growth rates on the sucrose chow were better than those on lactose chow. However, the better growth on sucrose chow could also reflect better digestion of sucrose than lactose at this age as a result of the relative activities of sucrase and lactase. Regardless of the reason, the use of sucrose chow allows weaning on day 17 without the interruption of growth that is usually seen with premature weaning. A beneficial effect of sucrose chow on growth of pups weaned at 16 days has recently been reported by other investigators (24); however, the effects were not as dramatic as those described here.

Another point of note regarding growth is that pups on the high carbohydrate solid diet containing lactose as sole carbohydrate (Fig. 2) grew better than pups on the analogous liquid diet (Fig. 4). Other authors (31) have reported similar findings for growth of older rats on a variety of liquid diets as compared with solid diets. This phenomenon may reflect a relative deficiency of one or more nutrients in the various liquid diets. Iron is a likely candidate because Bolton (3) has reported normal growth rates in rats fed a milk-based liquid diet with supplemental iron.

The principal finding of this study is that the level to which sucrase activity rises during the fourth postnatal wk is dependent on the relative proportions of carbohydrate and fat in the young animal's diet. Taken together with previous data $(8,13-17,20-22$, $34)$, this suggests that there are two phases in the ontogeny of this enzyme: (1) an early phase in which the appearance of the enzyme is cued by corticosterone and facilitated by thyroxine; and (2) a later phase in which the terminal maturation of the enzyme is dependent on the composition of the diet. The exact duration of these two phases has not yet been established.

\section{REFERENCES AND NOTES}

1. Beam, H. E., and Henning, S. J.: Development of the circadian rhythm of jejunal sucrase activity in the weanling rat. Am. J. Physiol., 235: 437 (1978).

2. Blair, D. G. R., Yakimets, W., and Tuba, J.: Rat intestinal sucrase. II. The effects of rat age and sex and of diet on sucrase activity. Can. J. Biochem. Physiol., 41: 917 (1963).

3. Bolton, R. W.: Rearing of gnotobiotic rodents by feeding a commercially-prepared infant formula. J. Nutr., 108: 812 (1978)

4. Boyle, J. T., and Koldovsky, O.: Critical role of adrenal glands in precocious increase in jejunal sucrase activity following premature weaning in rats: negligible effect of food intake. J. Nutr., 110: 169 (1980)

5. Castro, G. A., Copeland, E. M., Dudrick, S. J., and Johnson, L. R.: Intestinal disaccharidase and peroxidase activities in parenterally nourished rats. J. Nutr., 105: 776 (1975)

6. Deren, J. J.: Development of intestinal structure and function. In: C. F. Code Handbook of Physiology, Section 6, Alimentary Canal, Vol. III, p. 1099-1123 (American Physiology Soc., Washington, D. C., 1968).

7. Deren, J. J., Broitman, S. A., and Zamcheck, N.: Effect of diet upon intestina disaccharidases and disaccharide absorption. J. Clin. Invest., 46: 186 (1967)

8. Doell, R. G., and Kretchmer, N.: Intestinal invertase: precocious development of activity after injection of hydrocortisone. Science (Wash. D. C.), 143: 42 (1964)

9. Dymsza, H. A., Czajka, D. M., and Miller, S. A.: Influence of artificial diet on weight gain and body composition of the neonatal rat. J. Nutr., 84; 100 (1964).

10. Goldstein, R., Klein, T., Freier, S., and Menczel, J.: Alkaline phosphatase and 
disaccharidase activities in the rat intestine from birth to weaning. 1. Effect of diet on enzyme development. Am. J. Clin. Nutr., 24: 1224 (1971)

11. Greene, H. L., Stifel, F. B., Hagler, L., and Herman, R. H.: Comparison of the adaptive changes in disaccharidase, glycolytic enzyme and fructosediphosphatase activities after intravenous and oral glucose in normal men. Am. J. Clin. Nutr., 28: 1122 (1975).

12. Hatch, T. F., Lebenthal, E., Branski, D., and Krasner, J.: The effect of early postnatal acquired malnutrition on intestinal growth, disaccharidases and enterokinase. J. Nutr., 109: 1874 (1979).

13. Henning, S. J.: Permissive role of thyroxine in the ontogeny of jejunal sucrase. Endocrinology, 102: 9 (1978).

14. Henning, S. J.: Plasma concentrations of total and free corticosterone during development in the rat. Am. J. Physiol., 235: E451 (1978).

15. Henning, S. J.: Biochemistry of intestinal development. Environ. Health Perspect., 33: 9 (1979).

16. Henning, S. J., and Kretchmer, N.: Development of intestinal function in mammals. Enzyme, 15: 3 (1973).

17. Henning, S. J., and Sims, J. M.: Delineation of the glucocorticoid-sensitive period of intestinal development in the rat. Endocrinology, 104: 1158 (1979)

18. Kedinger, M., Simon, P. M., Raul, F., Grenier, J. F., and Haffen, K.: The effect of dexamethasone on the development of rat intestinal brush border enzymes in organ culture. Dev. Biol., 74: 9 (1980).

19. Koldovsky, O.: Development of functions of the small intestine in mammals and man. (S. Karger, Basel, 1969).

20. Koldovsky, O., Jumawan, J., and Palmieri, M.: Thyroxine-evoked precocious decrease in acid hydrolases in the ileum of suckling rats. Proc. Soc. Exp. Biol. Med., 146: 661 (1974).

21. Koldovsky, O., Krulich, L., Tenore, A., Jumawan, J., Horowitz, C., and Lau, H. Effect of triiodothyronine injection on levels of triiodothyronine and thyroidstimulating hormone in sera and milk of lactating rats and in sera of their sucklings; precocious development of jejunal $\alpha$-disaccharidases in the sucklings. Biol. Neonate, 37: 103 (1980).

22. Koldovsky, O., and Palmieri, M.: Cortisone-evoked decrease of acid $\beta$-galactosidase, $\beta$-glucuronidase, $N$-acetyl- $\beta$-glucosamidase and aryl sulphatase in the ileum of suckling rats. Biochem. J., 125: 697 (1971).

23. Lebenthal, E., Sunshine, P., and Kretchmer, N.: Effect of carbohydrate and corticosteroids on activity of $\alpha$-glucosidases in intestine of the infant rat. $\mathrm{J}$. Clin. Invest., 51: 1244 (1972).

24. Lerman, R., and Koldovsky, O.: Growth and food intake of prematurely weaned rats: effect of cortisone and thyroxine injection during the suckling period. $\mathrm{J}$. Nutr., 109: 916 (1979).
25. Lichtenberger, L., and Johnson, L. R.: Gastrin in the ontogenic development of the small intestine. Am. J. Physiol., 227: 390 (1974).

26. Lowry, O. H., Rosebrough, N. J., Farr, A. L., and Randall, R. J.: Protein measurement with the Folin phenol reagent. J. Biol. Chem., 193: 265 (1951).

27. Moog, F. The differentiation and redifferentiation of the intestinal epithelium and its brush border membrane. In: Development of Mammalian Absorptive Processes, Ciba Foundation Series 70, p. 31 (Excerpta Medica, Elsevier NorthHolland, Amsterdam, 1979).

28. Olsen, W. A., and Korsmo, H.: The intestinal brush border membrane in diabetes: studies of sucrase-isomaltase metabolism in rats with streptozotocin diabetes. J. Clin. Invest., 60: 181 (1977).

29. Raul, F., Simon, P. M., Kedinger, M., Grenier, J. F., and Haffen, K.: Effect of sucrose refeeding on disaccharidase and aminopeptidase activities of intestinal villus and crypt cells in adult rats. Biochim. Biophys. Acta, 630: 1 (1980).

30. Rosensweig, N. S., and Herman, R. H.: Control of jejunal sucrase and maltase activity by dietary sucrose or fructose in man: a model for the study of enzyme regulation in man. J. Clin. Invest., 47: 2253 (1968).

31. Sircar, B., Johnson, L. R., and Lichtenberger, L. M.: Effect of chemically defined diets on antral and serum gastrin levels in rats. Am. J. Physiol., 238: G376 (1980).

32. Stevenson, N. R., Ferrigni, F., Parnicky, K., Day, S., and Fierstein, J. S.: Effect of changes in feeding schedule on the diurnal rhythms and daily activity levels of intestinal brush border enzymes and transport systems. Biochim. Biophys. Acta, 406: 131 (1975).

33. Ulshen, M. H., and Grand, R. J.: Site of substrate stimulation of jejunal sucrase in the rat. J. Clin. Invest., 64: 1097 (1979).

34. Yeh, K., and Moog, F.: Development of the small intestine in the hypophysectomized rat. II. Influence of cortisone, thyroxine, growth hormone, and prolactin. Dev. Biol, 47: 173 (1975).

35. Younoszai, M. K., and Ranshaw, J.: Intestinal disaccharidases in the rat: effects of pregnancy and diabetes. J. Nutr., 106: 504 (1976).

36. The authors wish to thank Drs. D. S. Mailman and M. V. Rao for their helpful comments on the manuscript and Cheryl Wilson for her technical assistance.

37. The authors are very grateful to Alice Goldberg for winning $\$ 500$ worth of special diets by her artistic efforts.

38. Requests for reprints should be addressed to: Susan J. Henning, Ph.D., Department of Biology, University of Houston, Houston, Texas 77004 (USA)

39. This research was supported by grant HD 14094 from the National Institutes of Health.

40. Received for publication August 1, 1980.

41. Accepted for publication December I, 1980. 